\title{
Mobilidade urbana no contexto do município de Campina Grande/PB: uma abordagem à luz do paradigma das cidades sustentáveis
}

O objetivo principal deste artigo é analisar a concretude do plano diretor do município de Campina Grande/PB, com a intenção de resolver o seguinte problema: do ponto de vista técnico/empírico, a aplicação do plano diretor daquele município pode ser avaliada com base em dados sobre a frequência de uso do transporte público no período correspondente aos anos 2013 a 2018, obtidos através da realização de séries temporais? Para tanto, entende-se que esta pesquisa, longe de propor a solução de problemas recorrentes de mobilidade, se presta muito mais a lançar um novo olhar sobre o assunto, servindo de banco de dados para reflexão sobre questões políticas de mobilidade urbana, encontrando no paradigma da mobilidade sustentável seu ponto de partida e também o principal objetivo a ser alcançado. Para análise da tendência da série temporal utilizou-se o teste de Mann Kendall. Para observar as homogeneidades optou-se por realização de três testes: teste de homogeneidade normal padrão para um único ponto, teste de Pettitt e teste de Buishand. Os resultados encontrados na pesquisa mostram que existe uma tendência ao decrescimento desta demanda, e isto começou a acontecer de forma mais intensa no final de 2015, em contraponto ao aumento do número de viagens na cidade.

\section{Urban mobility in the context of the municipality of Campina Grande/PB: an approach in the light of the paradigm of sustainable cities}

The main objective of this article is to analyze the concreteness of the master plan of the municipality of Campina Grande/PB, with the intention of solving the following problem: as from the technical/empirical point of view, the application of the master plan of that municipality can be evaluated based on data on the frequency of use of public transport in the period corresponding to the years 2013 to 2018, obtained through the realization of time series? To this end, it is understood that this research, far from proposing to solve recurrent mobility problems, lends itself much more to launching a new look on the subject, serving as a database for reflection on policy issues of urban mobility, finding in the sustainable mobility paradigm its starting point and also the main objective to be achieved. Mann Kendall's test was used to analyze the trend of the time series. To observe the homogeneity, three tests were chosen: standard normal homogeneity test for a single point, Pettitt test and Buishand test. The results found in the research show that there is a tendency to decrease this demand, and this began to happen more intensely at the end of 2015 , in counterpoint to the increase in the number of trips in the city.

Keywords: Urban mobility; Sustainable mobility; Campina Grande Master Plan.

Topic: Planejamento Urbano

Reviewed anonymously in the process of blind peer.
Received: 03/02/2021

Approved: 26/02/2021
Augusto César Trigueiro Félix (1D)

Universidade Federal de Campina Grande, Brasil

http://lattes.cnpq.br/6414132347837894

http://orcid.org/0000-0001-8223-780X

augusto_cesar_3@hotmail.com

Isabel Lausanne Fontgalland (D)

Universidade Federal de Campina Grande, Brasil

http://lattes.cnpq.br/3447455428798868

http://orcid.org/0000-0002-0087-2840

isabelfontgalland@gmail.com

Amilson Albuquerque Limeira Filho (iD)

Universidade Federal de Campina Grande, Brasil

http://lattes.cnpq.br/7629201334907852

http://orcid.org/0000-0002-8375-6369

amilson.albuquerque@gmail.com

\author{
Andressa Pedroza Pereira (iD \\ Universidade Federal de Campina Grande, Brasil \\ http://lattes.cnpq.br/8506901843096968 \\ http://orcid.org/0000-0002-6297-7605 \\ andressapedrozap@gmail.com \\ Maria de Fátima Martins (D) \\ Universidade Federal de Campina Grande, Brasil \\ http://lattes.cnpq.br/5764682036707991 \\ http://orcid.org/0000-0002-9578-9555 \\ fatimamartins2005@gmail.com
}

Referencing this:

FÉLIX, A. C. T.; FONTGALLAND, I. L.; LIMEIRA FILHO, A. A.; PEREIRA, A. P.; MARTINS, M. F.. Mobilidade urbana no contexto do município de Campina Grande/PB: uma abordagem à luz do paradigma das cidades sustentáveis. Revista Ibero Americana de Ciências Ambientais, v.12, n.2, p.725-732, 2021. DOI: http://doi.org/10.6008/CBPC2179$\underline{6858.2021 .002 .0060}$ 


\section{INTRODUÇÃO}

A recorrência e continuidade do exercício reflexivo acompanhado de estudos, pesquisas e amplas discussões acerca das múltiplas dimensões que as cidades têm adquirido nos últimos séculos, viria a inaugurar um campo autônomo de conhecimento, cada vez mais próximo e marcado pelos vieses da inter ${ }^{1} \mathrm{e}$ transdisciplinaridade ${ }^{2}$, demonstrando a premente necessidade e relevância de temas conexos à cidade, hoje, bastante presentes em discussões acadêmico/científicas, mas que também se espraiam para além do escopo da ciência, alcançando os saberes tradicionais, a mídia, as expressões artístico-populares, a tradição jurídica, bem como os próprios fenômenos sociais de onde emergem, como outrora ponderou Ascher (2010), ao afirmar que as cidades são reflexos das sociedades que lhes abrigam.

Nesse lócus interdisciplinar, a dinamicidade dos fenômenos sociais pode ser sentida na própria complexidade dos fenômenos urbanos deles decorrentes, na proporção em que se agigantam antigos problemas preludiados com o que, outrora, ambientava os primórdios de uma Revolução Industrial, agora condicionados à dinâmica de uma sociedade marcada pelos reflexos da globalização, cada vez mais exposta a uma variedade infinda de riscos $^{3}$ e (re)dimensionada consoante interesses econômicos heterogêneos, revelando uma complexidade ínsita ao atual processo de urbanização que, não raramente, se fragmenta diante de interesses diversos e por vezes tão divergentes, demonstrando que a cidade é, enfim, espaço dialético de incansável aprimoramento, consolidado à luz de contínuas intersecções e tensionamentos.

A mobilidade urbana, nesse contexto, se insere enquanto questão crucial, ao integrar um novo modelo de urbanidade, agora não mais restrito à simplicidade arquitetônica que outrora interligava antigas estradas rurais e caminhos de terra, ao reivindicar novas pautas que perpassam desde temas históricos, como a função social da propriedade, a assuntos do cotidiano, como a urgência na construção e reestruturação de estradas, a consolidação de projetos urbanísticos que garantam o livre trânsito de pedestres em regiões centrais de determinadas municipalidades, ou ainda a elaboração de políticas públicas de incentivo ao uso de transporte público em localidades onde se constata ampla opção por veículos particulares.

Ademais, a realização de um plano global de mobilidade urbana proposto pela Organização das Nações Unidas (ONU), em 2013, intitulado "Planing and Design for Sustainable Urban Mobility", demonstra não só a relevância e abrangência do tema, como eleva o assunto a nível internacional, indicando certa urgência no enfrentamento de problemas que perpassam pela realidade de diversas nações e que repercutem, inclusive, no próprio destino do planeta, pondo em xeque o atual modelo desenvolvimentista, cujos desdobramentos se fazem sentir nos crescentes conflitos climáticos, nos problemas urbanos cada vez mais recorrentes e que reverberam em conflitos sociais pujantes e latentes, além de implicações na esfera ambiental em proporções igualmente alarmantes, que direta ou indiretamente encontram suas causas na ausência de adequado planejamento urbano.

\footnotetext{
${ }^{1}$ Segundo pontua Moraes (1997): Refere-se à tentativa empreendida com o fim de “[...]correlacionar disciplinas, descobrir uma axiomática comum entre elas".

${ }^{2}$ Na visão de Sousa et al. (2017): "A transdisciplinaridade favorece um diálogo vivo, promotor de uma abertura que visa à conjunção. Assim, consolidase como campo fértil na articulação entre os diferentes níveis de organização do conhecimento (disciplinaridade, multidisciplinaridade, pluridisciplinaridade, interdisciplinaridade), e em uma postura de transcendência, amplia-se para além deles".

${ }^{3}$ Cf.: BECK (1992), Risk Society: Towards a New Modernity, Londres, Sage.
} 
Diante de risível crise ambiental, urge dimensionar a multiplicidade de problemas socioambientais decorrentes da ausência de um planejamento de mobilidade urbana, ou ainda de sua inefetividade, assim sintetizados nos estudos de Faria et al. (2016) e que variam desde a emissão de gás dióxido de carbono, principal fator desencadeador do aquecimento global, até a diminuição na oferta de transporte público de qualidade pelo Poder Público, repercutindo no aumento do uso de transporte individual, o que traz consigo, ainda, uma série de desdobramentos e que podem ser resumidos na impossibilidade de contenção da poluição, gerando prejuízos concretos à saúde de habitantes de grandes centros urbanos, além do aumento no uso de recursos naturais (VASCONCELLOS, 2001). Além disso, ipsis litteris:

$\mathrm{Na}$ atualidade os sistemas de transporte urbano nas regiões metropolitanas são extremamente complexos e preveem a multimodalidade. No entanto, os problemas enfrentados, relacionados à poluição ambiental local e global, aos congestionamentos, à falta de segurança e à ineficiência dos sistemas de transportes, estes últimos especialmente no Brasil, têm gerado uma série de questionamentos e redirecionamentos de políticas públicas de mobilidade urbana. É premente, nesse contexto, a necessidade de se repensar a mobilidade urbana que está inserida nas cidades com toda sua história e características naturais. As mudanças devem considerar a complexidade desse espaço urbano para propor soluções que não podem excluir a mobilidade a pé como tem ocorrido. (FARIA et al., 2016)

De modo análogo, o crescimento urbano nos últimos 50 anos tem se apresentado de modo igualmente problemático (RATTNER, 2009), demandando espaços cada vez mais amplos, integrados e sofisticados, aptos à promoção de uma infraestrutura complexa capaz de equacionar interesses dos mais diversos e que variam desde necessidades básicas como transporte e saneamento básico, até exigências burocráticas de difícil implementação, planejamento a longo prazo e o emprego de esforços nos mais diversos campos com vistas à integração de distintos interesses sociais (LOUREIRO et al., 2013), sendo consenso entre muitos estudiosos de que se trata de verdadeira causa motriz da maior parte de problemas relacionados à mobilidade.

Para todos os efeitos, há de se ter em mente que o problema da mobilidade urbana perpassa, pelo menos, três esferas, a saber: social, econômica e ambiental, o que pode ser constatado não apenas pela abrangência ou relevância do tema, mas sobretudo pelas suas implicações práticas, mormente do ponto de vista social, quando se passa a considerar qualidade de vida como fator desencadeado pela efetivação de políticas de mobilidade urbana, onde o tráfego de veículos e de pedestres passa a ser visto para além de seu aspecto meramente estrutural, passando a se considerar igualmente condicionantes socioeconômicas como idade, trabalho, renda e moradia dos usuários de transportes, bem como a demanda por veículos coletivos, públicos ou privados, o que certamente impacta na própria efetivação do direito de ir e vir (ARAÚJO et al., 2011).

Circunstância que sugere, enfim, que a própria ideia de mobilidade passa a ser revisitada de forma interdisciplinar e conectada aos pilares que sustentam o paradigma da sustentabilidade, razão pela qual se parte à investigação empírica de sua concretude, tendo por base o estado de arte da mobilidade urbana no município de Campina Grande/PB, com a intenção de se resolver a seguinte questão: como do ponto de vista técnico/empírico, a aplicação do Plano Diretor de referida municipalidade pode ser avaliada com base em dados relativos à frequência de uso de transportes públicos em período correspondente aos anos de 2013 a 
2018, obtidos por meio da realização de série temporal?.

Para tanto, parte-se do entendimento de que referida pesquisa longe de se propor à resolução dos problemas de mobilidade, presta-se muito mais ao lançamento de novo olhar sobre o tema, servindo de base de dados para reflexão de assuntos relacionados à políticas de mobilidade urbana, encontrando no paradigma da mobilidade sustentável seu ponto de partida e também objetivo maior a ser alcançado, se fazendo necessário, no entanto, que a letra da lei e o agir político se assentem em bases reais e factíveis, consolidando, assim, um novo modelo de desenvolvimento harmonizado com os ideais de sustentabilidade urbana $^{4}$

\section{METODOLOGIA}

Pela natureza e objetivos propostos, a metodologia utilizada neste estudo foi a do tipo série temporal, com abordagem quanti-qualitativa. Uma série temporal, também denominada série histórica, pode ser definida como uma sequência de dados obtidos em intervalos regulares de tempo durante um período específico (EVERITT, 1995; MORETTIN et al., 1985). Para realçar as propriedades de uma série temporal, esta é decomposta em três componentes: tendência, sazonalidade e ruído branco ou erro aleatório. A tendência é o efeito em longo prazo na média; a sazonalidade são os efeitos ligados às variações sazonais (semanal, mensal, anual, ...) com referida componente se repetindo a cada intervalo fixo "s"; já o ruído branco ou erro aleatório é a parte não explicada, que se espera ser puramente aleatória e compreende a variabilidade intrínseca aos dados e que não pode ser modelada, ou seja, consiste em tudo aquilo que não é explicado pelas outras componentes da série (SOUZA et al., 2009).

A pesquisa foi realizada com base nos dados do município de Campina Grande/PB, cuja população, por volta do ano de 2019, estima-se em 409.731 habitantes, com densidade demográfica de 648,31 hab/km² (IBGE, 2019). Nesse contexto, se perfaz com base em dados obtidos junto à Superintendência de Trânsito e Transportes Públicos (STTP), sendo estes considerados dados secundários, cuja leitura permite aferir a frequência na utilização do transporte público no município de Campina Grande, em período correspondente aos anos de 2013 a 2018. Para análise da tendência utilizou-se o teste de Mann Kendall. Nesse sentido, referido teste considera que, na hipótese de estabilidade de uma série temporal, a sucessão de valores ocorre de forma independente e a distribuição de probabilidade deve permanecer sempre a mesma (série aleatória) (MANN, 1945; KENDALL, 1975).

Para observar as homogeneidades optou-se por realização de três testes: teste de homogeneidade normal padrão (SNHT, Standard Normal Homogeneity Test) para um único ponto (ALEXANDERSSON et al., 1997), teste de Pettitt (PETTITT, 1979) e teste de Buishand (BUISHAND, 1982). Ademais, referidos testes estabelecem como hipótese nula, que a variável é independente e identicamente distribuída (iid). De outro modo, partindo de hipótese alternativa assumem um desvio na média.

Convém ressalvar, ainda, que o SNHT é mais sensível em detectar descontinuidades no início e no

\footnotetext{
${ }^{4}$ A Lei da Política Nacional da Mobilidade Urbana estabelece em seu art. 50, inciso II, "o desenvolvimento sustentável das cidades, nas dimensões socioeconômicas e ambientais".
} 
final da série, enquanto que os testes de Pettitt e Buishand são mais suscetíveis à localização de heterogeneidades no meio da série (MARTíNEZ et al., 2011). Nessa perspectiva, referida análise ao indicar a frequência de uso do transporte público no município de Campina Grande-PB, serviu de subsídio para avaliação de aplicação de seu Plano Diretor no que tange à mobilidade urbana, norteando a temática no contexto apresentado e considerando suas intersecções e desafios consoante o paradigma da sustentabilidade.

\section{RESULTADOS E DISCUSSÃO}

\section{Testes de Homogeneidade}

Os três testes de homogeneidade foram aplicados para série em estudo e são apresentados na Tabela 1. Todos os três resultados foram favoráveis à hipótese alternativa em que se afirmar a existência de uma data onde houve alteração nos dados. O gráfico dos testes foi gerado com as duas médias nos dois níveis encontrados nos testes (Figura 1). Observa-se no gráfico que a média do primeiro nível é sempre maior que a do segundo, o que indica uma queda na demanda deste modal no período estudado.

Tabela 1: Resultados dos testes de Homogeneidade.

\begin{tabular}{llll} 
Testes de Homogeneidade & p-valor & $\mathbf{t}$ & Hipótese aceita \\
\hline Teste de Pettitt & $<0,0001$ & Dez/15 & Ha: Há uma data em que houve alteração nos dados \\
Teste de Buishand & $<0,0001$ & Ago/16 & Ha: Há uma data em que houve alteração nos dados \\
Teste de SNHT & $<0,0001$ & Dez/16 & Ha: Há uma data em que houve alteração nos dados
\end{tabular}

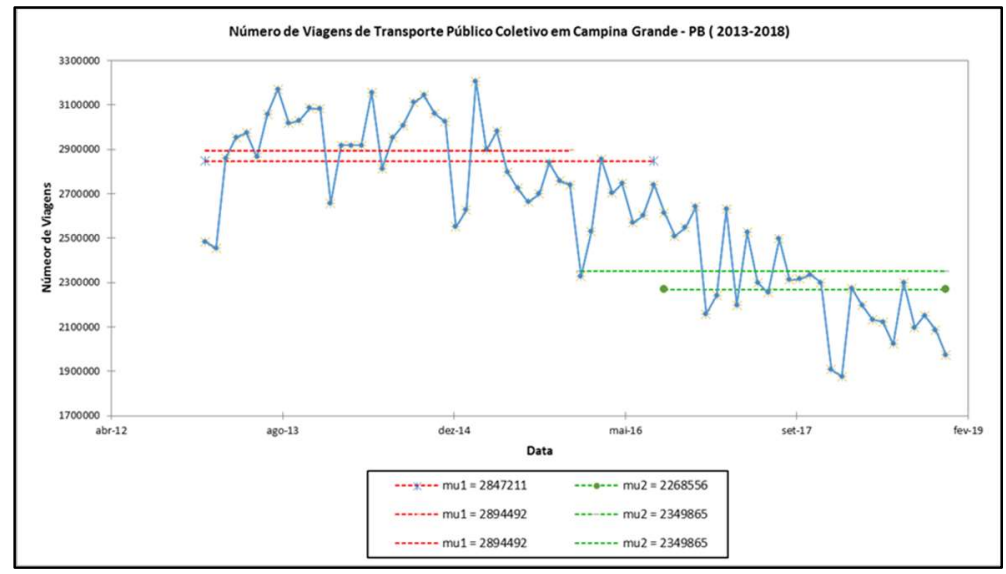

Figura 1: Gráfico gerado a partir dos Testes de Homogeneidade.

\section{Teste de Mann-Kendall}

O teste de Mann-Kendall foi aplicado nas três possibilidades possíveis de quebra, tanto no primeiro nível da série quanto no segundo nível. Inicialmente usando a quebra em Dezembro de 2015, depois a de Agosto de 2016 e posteriormente a de Dezembro de 2016. Os resultados dos testes estão na Tabela 2.

Tabela 2: Resultados do Teste de Mann-Kendall.

\begin{tabular}{lllll} 
& Primeiro nível & & Segundo nível \\
\hline $\mathbf{T}$ & $\mathbf{p}$-valor & Hipótese aceita & p-valor & Hipótese aceita \\
Dez/16 & 0,379 & Não existe tendência & $<0,0001$ & Existe uma tendência \\
Ago/16 & 0,009 & Existe uma tendência & $<0,0001$ & Existe uma tendência \\
Dez/16 & $<0,0001$ & Existe uma tendência & 0,004 & Existe uma tendência \\
\hline
\end{tabular}


Através dos resultados obtidos no teste de Mann-Kendall observa-se que a quebra de nível na data de dezembro de 2015 apresenta maior relevância para o estudo, pois foi o único resultado em que se revelou não haver indícios de tendência no intervalo em questão. Isto indica que existe uma evidência de alteração do comportamento da demanda de transporte neste período, sendo, nessa perspectiva, necessária a investigação dos possíveis fatores que o provocaram.

\section{Testes de Raiz Unitária e Estacionariedade}

Complementando a aplicação dos testes na série temporal do estudo, aplicou-se os testes de DickeyFuller e KPSS para a verificação da estacionariedade na série. Incialmente se aplicou os testes referidos no primeiro nível encontrado anteriormente, no período de Janeiro de 2013 a Dezembro de 2015, e depois no segundo nível, no período posterior de Janeiro de 2016 a Dezembro de 2018. Os resultados se encontram na Tabela 3.

Tabela 3: Resultados dos Testes de Estacionariedade.

\begin{tabular}{lllll} 
& \multicolumn{2}{l}{ Primeiro Nível } & \multicolumn{2}{l}{ Segundo Nível } \\
\hline & p-valor & Hipótese aceita & p-valor & Hipótese aceita \\
\cline { 2 - 5 } Teste de Dickey-Fuller & 0,0742 & H0: Há uma raiz unitária para a série & 0,1056 & H0: Há uma raiz unitária para a série \\
Teste de KPSS & 0,2414 & H0: A série é estacionária & $<0,0001$ & Ha: A série não é estacionária \\
\hline
\end{tabular}

\section{Discussão dos Resultados}

Através dos resultados encontrados nos testes aplicados da série histórica pode-se supor que existiu algum fator influenciador no comportamento da variável que a fez permanecer em um estado de estacionariedade e de não tendência no primeiro intervalo da série, no período de Janeiro de 2013 á Dezembro de 2015. Uma possiblidade, que vai de acordo com a lei de oferta e procura, é o fato de que no ano de 2013 a prefeitura de Campina Grande-PB subsidiou a tarifa de ônibus, baixando o preço em $\mathrm{R} \$ 0,10$. Nesse caso, abaixo do aprovado pelo conselho municipal de transporte na época, sendo com isso uma variação menor que a inflação do mesmo ano.

Segundo Campos (2006), o conceito de mobilidade urbana sustentável pode ser compreendido em dois contextos, o ambiental e o socioeconômico. No contexto socioeconômico, uma estratégia que se propõe é uma " tarifa adequada a demanda e oferta do transporte público". Nesse caso, entende-se que no período inicial do estudo essa tarifa esteve adequada a essa estratégia, na medida em que não houve queda na quantidade demandada e com isso mantendo-se a oferta de transporte público constante. Uma das diretrizes do Plano Nacional de Mobilidade Urbana (Lei 12.587/12) é a prioridade dos serviços de transporte público coletivo sobre o transporte individual motorizado. Neste sentido, percebe-se que a ação do poder público municipal em subsidiar a tarifa de ônibus esteve de acordo com a referida Lei (BRASIL, 2012).

Com relação ao segundo nível da série, o fenômeno observado da demanda de transporte público encontra-se de acordo com o que Rogers (2012) observou nos principais centros urbanos no mundo. Segundo o autor, nas últimas décadas do século XX aconteceu um grande crescimento de automóveis nos países capitalistas. Na Europa, por exemplo, entre 1970 e 1995 o número de carros dobrou, o que para o autor teve 
como principal causa o apoio dos Países Europeus às indústrias de automóveis. Esse estímulo também aconteceu no Brasil e provocou uma facilidade de acesso ao consumo de automóveis e motocicletas nas últimas décadas, com a chegada de montadoras multinacionais, como a Honda, que conseguiu dominar o mercado de motocicletas no Brasil.

O resultado obtido sobre a tendência decrescente da série encontra-se de acordo com Carvalho et al. (2011) que ao observarem o crescimento do uso do transporte individual - desde meados dos anos 1990 - percebeu-se que a demanda por transporte público sofreu quedas frequentes. Várias foram as políticas econômicas, adotadas pelos governos, que reforçaram o estímulo ao transporte individual, sendo estas um dos fatores pela diminuição no uso do transporte coletivo. Além disso, os resultados podem ser comparados com os encontrados na análise do NTU em 2013, que afirma que 90\% da demanda de transporte público tiveram sua demanda encolhida em cerca de $25 \%$ desde essa época, apesar da tendência de estabilização do volume de passageiros observada recentemente, em função do aumento de renda dos mais pobres.

\section{CONCLUSÕES}

Com o Plano Nacional de Mobilidade Urbana instituído em 2015, a prioridade das ações dos gestores sobre o planejamento urbano foi voltada para o incentivo da transporte público coletivo e transporte nãomotorizado, e isto está presente em várias partes do referido documento. O Plano De Mobilidade Urbana de Campina Grande inspirado por esse Plano Nacional também tem nos seus princípios e diretrizes o incentivo e a qualidade da oferta do serviço desse modal de transporte.

Isto, porém, não ficou perceptível na demanda de transporte público encontrada no período correspondente aos anos de 2013 a 2018. Os resultados encontrados na pesquisa mostram que existe uma tendência ao decrescimento desta demanda, e isto começou a acontecer de forma mais intensa no final de 2015, em contraponto ao aumento do número de viagens na cidade. Algumas possíveis causas desta diminuição seriam o aumento na aquisição de veículos motorizados, causado pelos incentivos ao crédito implementados pelos governos anteriores, o que possivelmente teria ocasionado progressivo aumento da tarifa de transporte público, seguindo uma lógica de oferta e demanda tendente à ampliação com a diminuição da oferta.

Além disso, percebe-se que no período em que a Prefeitura Municipal subsidiou a tarifa de transporte público, a demanda encontrou-se estacionária e em alguns meses teve relativo crescimento. Tal fato indica que uma possível solução para essa problemática pode estar em uma atuação mais ativa por parte do poder público, tendo em vista que a mobilidade urbana consiste em verdadeiro impulso ao desenvolvimento econômico, o que sugere que no decorrer do processo de tomada de decisões por parte da Administração Pública, ações de incentivo à mobilidade urbana na sua acepção sustentável podem não só melhorar significativamente a economia local, gerando com isso mais empregos e aumento de renda real da população campinense, como podem, enfim, contribuir efetivamente na busca por novos modelos de desenvolvimento urbano capazes de harmonizar o direito de ir e vir com as demandas do processo de urbanização.

Sugere-se, assim, a busca conjunta e contínua pelo Poder Público, iniciativa privada e demais setores 
da sociedade, pela relativa estabilidade entre as esferas ambiental, social e econômica, de modo a se tornar factível a efetivação de uma política de mobilidade urbana, em que a cidade passa a ser vista não apenas como um espaço de crescimento econômico ou de trânsito de veículos, mas, sobretudo, enquanto lugar onde a vida se desenvolve com dinamismo e dignidade.

\section{REFERÊNCIAS}

ALEXANDERSSON, H.; MOBERG, A.. Homogenization of Swedish temperature data. Part I: homogeneity test for linear trends. International Journal of Climatology, v.17, p.25-34, 1997.

NTU. Associação Nacional das Empresas de Transporte Urbano. Anuário NTU: 2012/2013. Brasília: NTU, 2013.

ARAÚJO, M. R. M.; OLIVEIRA, J. M.; JESUS, M. S.; SÁ, N. R.; SANTOS, P. A. C.; LIMA, T. C.. Transporte público coletivo: discutindo acessibilidade, mobilidade e qualidade de vida. Psicologia \& Sociedade, v.23, n.3, p.574-582, 2011.

ASCHER, F.. Os Novos Princípios do urbanismo. São Paulo: Romero Guerra, 2010.

BRASIL. Lei n. 12.587, de 3 de janeiro de 2012. Institui as diretrizes da Política Nacional de Mobilidade Urbana. Brasília: DOU, 2012.

BUISHAND, T. A.. Some methods for testing the homogeneity of rainfall records. Journal of Hydrology, v.58, p.11-27, 1982.

CARVALHO, C. H. R.; PEREIRA, R. H. M.. Efeitos da variação da tarifa e da renda da população sobre a demanda de transporte público coletivo urbano no Brasil. Brasília: IPEA, 2011.

EVERITT, B. S.. The Cambridge dictionary of statistics in the medical the medical sciences. Cambridge: Cambridge University Press, 1995.

FARIA, H. M.; LIMA, C. A.. Andar a pé mobilidade urbana e sustentabilidade nas regiões metropolitanas brasileiras. Laboratório de Estudos Urbanos do Núcleo de Desenvolvimento da Criatividade, n.22, v.1, p.125-149, 2016.

IBGE. Instituto Brasileiro de Geografia e Estatística. Cidades e Estados. Campina Grande. IBGE, 2019.
LOUREIRO, M. M.; GREGORI, I. C. S.. Como construir cidades sustentáveis?. Revista Eletrônica do Curso de Direito da UFSM, v.8, n.3, p.458-469, 2013.

MANN, H. B.. Non-parametric test against trend.

Econometrika, v.13, p.245-59, 1945.

MARTÍNEZ, M. D.; SERRA, C.; BURGUEÑO, A.; LANA, X.. Short Communication Response to the comments on time trends of daily Maximum and minimum temperatures in Catalonia (NE Spain) for the period 1975-2004. International Journal of Climatology, v.3, p.153-157, 2011.

MORAES, M. C.. O paradigma educacional emergente. 16 ed. Campinas: Papirus, 1997.

MORETTIN, P. A.; TOLOI, C. M. C.. Previsão de séries temporais. 2 ed. São Paulo: Atual, 1985.

PETTITT, A. N.. A non-parametric approach to the changepoint problem. Applied Statistics, v.28, n.2, p.126-135, 1979.

RATTNER, H.. Prefácio. In: ACSELRAD, H.. A duração das cidades: sustentabilidade e risco nas políticas urbanas. 2 ed. Rio de Janeiro: Lamparina, 2009.

ROGERS, R.; GUMUCHDJIAN, P.. Cidades para um pequeno planeta. São Paulo: Gustavo Gili, 2012.

SOUZA, A. M; GEORGEN, R.; FERRAZ, S. E. T.. Previsão de precipitação e temperatura em Santa Maria por meio de um modelo estatístico. Ciência e Natura, v.31, n.1, p.49-64, 2009.

SOUSA, J. G.; PINHO, M. J.. Interdisciplinaridade e transdisciplinaridade como fundamentos na ação pedagógica: aproximações teórico-conceituais. Signos, Lajeado, v.38, n.2, p.93-110, 2017.

VASCONCELLOS, E. A.. Transporte Urbano, espaço e equidade: análise das políticas públicas. 3 ed. São Paulo: Annablume, 2001.

A CBPC - Companhia Brasileira de Produção Científica (CNPJ: 11.221.422/0001-03) detém os direitos materiais desta publicação. Os direitos referem-se à publicação do trabalho em qualquer parte do mundo, incluindo os direitos às renovações, expansões e disseminações da contribuição, bem como outros direitos subsidiários. Todos os trabalhos publicados eletronicamente poderão posteriormente ser publicados em coletâneas impressas sob coordenação da Sustenere Publishing, da Companhia Brasileira de Produção Científica e seus parceiros autorizados. Os (as) autores (as) preservam os direitos autorais, mas não têm permissão para a publicação da contribuição em outro meio, impresso ou digital, em português ou em tradução. 